\title{
HEBERDEN ORATION，1965*
}

\section{REFLECTIONS ON THE CONTROLLED TRIAL}

BY

\author{
AUSTIN BRADFORD HILL
}

I cannot claim to be by nature "bloody, bold and resolute". My audacity in accepting the honour of giving the Heberden Oration for 1965 was, rather, the product of two environmental factors-my knowledge of rheumatologists and the statistical views of the poet William Cowper.

Under the first heading one of the more euphoric side-effects of nearly twenty years of work in clinical trials has bzen my contact with many of the leaders of your profession-and with the great advantage that I have not had to consult them professionally. In no speciality have I been more kindly received, and in none have I made more friends than in the field of rheumatology. That was, indeed, a source of courage. I could rely upon a continuing charity.

And then, having talked much in my time of clinical trials, I was emboldened by William Cowper's sagacious couplet:

"Tis hard if all is false that I advance-

A fool must now and then be right by chance."

Who knows? Perhaps it could be today that the $\mathbf{0} .05$ level would turn up.

\section{The Growth of the Controlled Trial}

It is not far off twenty years since the Medical Research Council published the results of its trial of the new antibiotic streptomycin in the treatment of pulmonary tuberculosis (M.R.C., 1948). This it was that set off the population explosion in controlled trials until now they appear in a continual and widely ranging stream in the weekly and specialist medical journals.

Limiting attention merely to the weekly journals and to the last twelve months, controlled trials have extended from an ointment for herpes simplex to a low-fat diet in myocardial infarction, from drugs in the treatment of the alcohol-withdrawal syndrome

* Delivered on November 12, 1965. to prophylactic penicillin for unconscious poisoned patients, from radiotherapy for herpes zoster to conservative or surgical treatment of anterior communicating aneurysms.

In short, over the whole scale from the trifling to the moribund.

They have even invaded the patter of the salesman. "A double-blind cross-over trial on 22 patients has shown that $\mathrm{XYZ}$ is the wide-spectrum antibiotic of choice." What would doctors have made of that 20 years ago? One may doubt whether it would have been a good selling point. Presumably it is to-day; clearly it is thought to be so.

The history of science, however, shows that frequently with a new discovery, a new technique, or a new theory of disease, the pendulum at first swings too far. Has this been so with the controlled trial? Is it true, as Cromie (1963) has suggested, that "little or no credence is now given to clinical observations even by experienced investigators" while there is "a blind acceptance of double-blind trials without a critical evaluation of their short-comings and their ability to mislead as well as to lead".

On the one hand two very experienced workers, Binns and Butterfield (1964), feel that the present quality and scale of clinical trials are an "increasingly serious bottleneck in the development and effective use of drugs".

While better use could be made of existing ways and means, they argue strongly and persuasively for additional resources-more academic departments of clinical pharmacology, research fellowships in clinical trials and, perhaps, an Institute of Therapeutics. In short, more and better controlled trials.

On the other hand Sir Robert Platt, provocatively inverting the customary aphorism, asks "why experiment, why not think?" (Platt, 1964). A passion for scientific experiment might have impeded progress by the methods of direct observation and the testing of hypotheses. 
And so the time has come, perhaps, when it would be opportune for us to relax and reflect. However, in so doing it is imperative that we draw no precise line between observation and experiment. It is just 100 years since the great experimentalist Claude Bernard (1865) wrote: "a physician observing a disease in different circumstances reasoning about the influence of these circumstances and deducing consequences which are controlled by other observations - this physician reasons experimentally even though he makes no experiments." And Sir Robert Platt himself has stressed that research is not just a matter of laboratories and test-tubes; it is an attitude of mind. Given the right attitude of mind, there is more than one way in which we can study therapeutic efficacy.

Any belief that the controlled trial is the only way would mean not that the pendulum had swung too far but that it had come right off its hook. We need not argue, therefore, over the semantics of observation and experiment. What we can more profitably reflect upon is whether the modern controlled trial is a useful adjunct to therapeutics, whether it asks the right question or questions, whether there is any way in to-day's more sophisticated and computerized setting by which it could be appreciably improved?

\section{The InadeQuate Trial}

At present some of the many controlled trials that are published fall lamentably short of what is really required of such an exercise. The authors do not appear to have asked themselves at the outset the deceptively simple but dominating question, "what precisely am I trying to find out?"'

At the end of a trial we are not interested (from the scientific viewpoint) in saying that we have found these things to be good for a particular group of patients-for the particular Tom, Dick, and Harry upon whom without thought we inflicted our drugs or our knives.

Invariably we wish to generalize from our results - that this treatment is of value in the treatment of a certain type of patient. Implicit, therefore, in the design of any trial must be a very careful definition of the type, or types, that we shall admit to it, and a very careful attempt to admit a true cross-section of patients conforming to those types.

Only thus can we safely generalize, and-equally important-only thus can we realize that outside this defined group we are extrapolating from our results. Often we shall certainly and rightly wish to extrapolate; we ought to be in a position to do so knowingly and with a recognized, even if not a measurable, risk.
Yet too often, in my capacity as a member of thD Committee on Safety of Drugs and of its Sube Committee on Clinical Trials, I am faced with trialsె on such an ill-defined, or undefined, pot pourri of patients that I can but hopelessly speculate upon. who got what and when and usually why?

These poorly-constructed trials not only teach us nothing but may even be dangerously misleading $-\frac{5}{0}$ particularly when their useless data are spuriously supported by all the latest statistical techniques and jargon. "Blinding with science" becomes almost an meiosis.

Another weakness lies in too crude a measure of $\vec{P}$ the results of a trial. As pointed out by Cromie, $\vec{a}$ high degree of sensitivity was not needed in the trial of antibiotics for the treatment of acute fevers. Bue that advantage certainly cannot be thoughtlessly? carried over into to-day's comparisons of, say, thes effects of analgesics and tranquillizers. No significant difference (in both senses) will almost certainly be the् answer if our measures of response are insensible ${ }_{\circ}$ Clearly, a great deal of thought and study must go into making them more sensitive before we can ask a useful question of the controlled trial. At present too many trials are launched without that precaution.

\section{Biological VARIABILITY}

Another problem lies in the biological variation the human material with which we have to deal. Can we make a useful trial if that variability is veryo great?

Sir Robert Platt thinks not and has suggested, by way of example, that the trials of anti-coagulanto treatment in coronary artery disease have failed to give a clear answer because so many variables are involved. Maybe that is so and that we should first make a more intensive study of the condition to ensure a greater degree of homogeneity in the trial ${ }^{\circ}$ patients.

Clearly our predecessors would not have got a very useful answer by applying one and the same treatment to a mixture of patients suffering from typhoid 0 and typhus fevers, before those conditions were accurately differentiated from one another. There is no doubt that this is an important point and one to be invariably considered before setting up a trial. $N$ As already asked above-can one make the question N asked precise? Can one adequately define a type? N On the other hand, in this field of coronary artery $\sigma$ disease, I wonder whether we would not get a clear answer in a trial of trinitrin tablets in the treatment of angina pectoris. Certainly we could expect to $\stackrel{D}{\oplus}$ observe an answer strongly in favour of insulin in the similarly widely varying field of diabetics. In other 
words the lack of clear-cut evidence for or against the long-term administration of anti-coagulants may come rather from the fact that their benefits are only marginal. It is that marginality, though perhaps combined with biological variability, that makes the results obscure.

In spite of this there are two strong arguments in favour of conducting these trials. In the first place, without having done so would we have known (at least for a long time) that the case for the plaintiff was so weak? Without that evidence would we not have been almost compelled to go on using them, on perhaps even a life-long basis and over the whole gamut of biological variability?

Secondly, such trials might well be one way of narrowing that variability-by their identification of some sub-group of patients who do tend to respond favourably to the treatment. With only a marginal value over the whole range of patients admitted we may, nevertheless, in our analysis of the observations, be able to pin-point an advantage much more than marginal in a particular domain.

\section{The Search for Limited Effects}

Here I find myself in complete disagreement with Sir John McMichael (1964); he has written that "the aim of a statistical trial is to include all the unpredictable multitude of factors which can influence the outcome by a comprehensive sample. Unless the treatment shows a convincing difference in outcome in the whole group it is not permissible to separate out afterwards a sub-division of better results. Any sub-divisions should be done on other criteria before the trial begins." McMichael is, in fact, criticizing the analysis of the Medical Research Council report on long-term treatment with anti-coagulants in terms of age and sex, two features in prognosis which invariably and so obviously call for divided attention that there could never be any question of before and afterwards (M. R. C., 1964).

But taking the issue further I can myself see no argument in favour of his view, either statistical or logical. If there is an "unpredictable multitude of factors which can influence the outcome", then surely it is our job, and duty, to see whether in the analysis we can identify them and thus make them predictable.

Of course, as Pasteur observed, if we are looking for something there is the danger that we may find it. And there is the danger that if we take twenty bites at the cherry we shall at one time bite off a "significant" chunk. In short, in our comprehensive search, we may be misled by an association that is not causation. But surely, to parody the poet, "tis better to have looked and lost than never to have looked at all".

To seek through one's data for clues, with an exacting conscience and with a cautious outlook, is demanded of every investigator. The clue may well be no more than a clue. Certainly we may not wish to draw conclusions. But with a bit of luck we may have learned something that we can put to the test in future observations, and perhaps in a further trial.

\section{THE GROUP AND THE INDIVIDUAL}

This leads directly to a related criticism of the present controlled trial-that it does not tell the doctor what he wants to know. It may be so constituted as to show without any doubt that treatment $A$ is on the average better than treatment $B$. On the other hand, that result does not answer the practising doctor's question what is the most likely outcome when this drug is given to a particular patient?

Is there indeed any way of answering that? To begin with I look back to the early days of controlled trials in rheumatology and in other illnesses some 10 to 15 years ago. There were then, it would be fair to say, still relatively few drugs in medicine that really worked. We had, therefore, a simple question to answer-does this drug work?

There were clinicians-perhaps not all that many -eager to learn any new way of approach but unfamiliar with the statistical experimental procedure and determined (very rightly) not to be mystified by the initiated. In short, simple questions were likely to find favour.

To-day we have a very different setting. There are many drugs that work and work potently. We want to know whether this one is more potent than that, what dose is right and proper, for what kind of patient. And so we have more elaborate and difficult questions to answer but also a developed and favourable climate of opinion and knowledge which allows the answers to be sought. No doubt we should now use a more sophisticated approach. I am, however, by no means convinced that we asked the wrong question of our trials of the treatment of early cases of rheumatoid arthritis (as has been said). What we found was "remarkably little to choose between cortisone and aspirin in the management of this group of patients" (M.R.C., 1954). The operative word is "group".

There is, of course, no suggestion that aspirin could supplant cortisone (or vice versa) in all cases and no such inference could possibly be warranted. Nevertheless, does not the finding give useful advice to the doctor faced with the individual patient? His first ambition, no doubt, will be to maintain the patient's health and well-being on no 
drugs at all (ethically the trial could have no such group). If that venture fails then he knows from the trial that he has two medicaments to which he can turn and that on the average one has shown no superiority over the other. Doubtless he will first select the one that is likely to produce the fewest adverse reactions. If that fails then he turns to the alternative. I submit that this is not a trivial contribution to his task.

However, in a more sophisticated trial, can we now go further? Can we identify the individual patient for whom one or the other of the treatments is the right answer? Clearly that is what we want to do and present-day investigators ought to give far more attention to the problem. There are very few signs that they are doing so.

There are several ways in which this problem might be tackled. First, we might take note of considerably more characteristics that delineate the patient-whether measurable features or observations of qualities. At the conclusion of the trial we should be able to see which, if any, of these characteristics had been associated with a favourable response to a specific treatment. Thus we might learn to specify the traits of the patient that are required for success.

The danger here is that we overload the trial with irrelevancies from, upwards and downwards, the diameter of the umbilicus. It is no trouble to the modern computer to look after them, but someone has to make and record all these observations, someone has to programme them for the computer, and someone has to study the answers it gives.

I agree with Hamilton (1965) that "it would be better to resist the temptation to collect every kind of information and spend the time first in thinking more carefully about what would be relevant, and to devise hypotheses to be tested".

The trouble is that with many diseases and many treatments we are too ignorant to know where even to begin to look.

This brings me to a second course of action - the skilled observation of the clinician at the bedside during a trial. Far from weakening the need for the skilled observer, the controlled trial should increase the demands. It most certainly must do so if part of the protocol of a trial is the attempt to identify features in the patient that favour, or disfavour, response to a specific treatment. That will call for a prepared and percipient mind.

A more purely statistical and interesting device has been put forward by Armitage (1965). With the cross-over form of trial, the more frequent the replication of each treatment on an individual the greater will be the chance of detecting any interaction between patients and treatments. Thus the greater? will be the chance of identifying the best treatment for a particular patient. If these findings could theng be related to the characteristics of that patient, a rule of choice of treatment could be provided for? future cases.

The patient as his own control implies, of course that he returns to the status quo after treatment. Inf Armitage's setting he would have to return to $\mathrm{i} \overline{\frac{5}{5}}$ repeatedly and this requirement must inevitably limie the application to chronic conditions and mainly tơ palliative treatments. But in such a situation io might prove to be a well worth-while approach.

\section{The Double-Blind Trial}

There is one feature of the modern controlled triat that frequently hampers the clinician in making acuter and discriminating observations of his patient-and that is the double-blind procedure.

This precaution may well be indispensible in deap ing with highly subjective signs and symptoms, such. as the assessment by patient and doctor of degrees of pain, discomfort, or anxiety. It may well be valun able in allowing, without bias or fear of bias, $\frac{C}{\mathbb{Q}}$ clinical judgement of the patient's state of well $\overrightarrow{a b}$ ill-being at any given time.

But in some situations I believe it may be ine dient and, indeed, injurious to the trial. Cromie has said, it is "ridiculous to scorn subjective assessments in subjective symptoms, and it is urg realistic to make artificially objective assessments". $\frac{\square}{\mathbb{Q}}$

Sometimes we can overcome this problem b having a division of labour-one to treat and one to assess. But there are situations in which $I$ would myself doubt the use of even that valuable procedure Such situations arise when it is important, for the sake of a realistic trial, that the doctor in charge of the patient be able to adjust the dose of a drug according to the patient's reactions and according his judgment of the patient's requirements. And he may then be the best judge of the result.

This is not easy to do under the double-blind prof cedure. It may well be asked, therefore, in the planning of a trial, which is the more important for the doctor to be ignorant of the treatment and unbiased in his judgment or for him to know what he is doing and to be able to adjust what he is doing so as to observe closely the results and then make unbiased judgments to the best of his ability and conscious mind?

The answer must turn upon circumstances, butत़ have myself little doubt that the double-blind methor is being used when it should not be the method of 
choice or that its limitations are not being overcome by careful planning.

\section{The Treatment OF ENURESIS}

I can illustrate my thesis by a brief and broad review of the literature describing the treatment of enuresis by means of the drug imipramine.

It all seemed to start in December 1960, with a little note and no sums from Australia to the American Journal of Psychiatry. This announced that the drug was effective in the majority of enuretic children when given in an evening dose of 25 or 50 mg. (according to age), that it ensured that most nights were dry even in those consistently wetting, and that the children relapsed when the drug was withdrawn.

This report gave a rather flickering impulse over the next 2 years to a number of uncontrolled observations, varying in number from 1 case to 26 but uniform in their verdict of successful. Then, in 1963 (after a rather vague account of a test on trainees in the U.S. Army), expectations are fulfilled and we find ourselves rapidly up to the hilt (perhaps not a good metaphor in this setting) in the double-blind, the cross-over, and the placebo.

The first investigator reports no specific effect whatever. This brings the inevitable retort that had a higher dosage been used we could all feel confident that the answer would have been favourable, and in turn, the retort more in sorrow than in anger-c"we do not like to relinquish favourable clinical impressions either but our figures and double-blind controlled facts are the reality we have to face" (Abrams, 1964).

The same gloomy reality characterizes the second attempt with the full double-blind cross-over placebo gambit, but this trial also leads its authors to speculate hopefully upon what a larger dose might have achieved.

Next in line we have a partial success: 23 boys were treated for 20 days on each of three "treatments"-nothing, a placebo, and a fixed dose of $25 \mathrm{mg}$. imipramine. Of the 426 nights of exposure 71 per cent. were wet on nothing, 70 per cent. on the placebo, and 47 per cent. on imipramine. With no treatment the last figure rose to 63 per cent. and with the restoration of imipramine it fell to 36 per cent. Yet no boy was wholly dry on the drug.

In 1964 we return to the U.S. Army and Navy and a dose of $50 \mathrm{mg}$. per suffering recruit per evening. No consolation is to be found in these observations, but those of the Navy meet with the customary reproach that the dose used was too low.

Similarly, we can draw but little solace from a small trial on nine affected children hospitalized and with neurotic symptoms, who were given $25 \mathrm{mg}$. at bedtime if under 12 years of age and $50 \mathrm{mg}$. if over 12 ; the improvement on imipramine is only slightly and not significantly different from that on the placebo

Finally, we end 1964 with a sequential design and the conclusion after eight pairs that imipramine is significantly better than the placebo. It is, perhaps, material here that the dose was made to depend upon the results of the first few nights.

On my reading of the literature (and I offer no guarantee that it is comprehensive), there are eight uncontrolled trials, all of which are favourable, and eight controlled trials, six of which are unfavourable. And constantly running through them is the plaintive plea-too small a dose.

Perhaps from this story there is a moral to be drawn-not only the old one of the need for controls but that in some circumstances the fixed dose may be gravely misleading and that the double-blind procedure has encouraged its adoption.

I lay stress on this because there is still a misunderstanding of the problem. In a recent leading article in the British Medical Journal (1965), discussing the U.K.-U.S.A. trial of the treatment of rheumatic fever, there is a reference to the different findings of Dr. May Wilson: "the important difference", it says, "between her principles of therapy and those in the controlled trials by the Anglo-American team are that she gave much larger doses of steroids for a shorter period and varied the dose not according to the weight or to any specified levels (as required in a trial) but by the patient's response."

The statement of fact is true. The parenthesis "as required in a trial" is quite false. Maybe, in this particular trial, carried out in the state of knowledge of the steroids of nearly 15 years ago and in many centres in three countries, it was necessary to standardize the dose. But that decision cannot be converted into a generalization.

The doctor, or team, working on the do-ityourself principle might, of course, decide to vary the dose in relation to their patient's responses. So also could it be organized in any wider multi-centre trial. What one has done is to propound a different question and to make it read: "if competent clinicians in charge of defined types of patients use drug $X$ in such varying amounts and for such varying durations of time, and so forth, as they think advisable for each patient, what happens." In fact I wrote that in 1952. As the cynical Frenchman said, "everything has been said before but as no one appears to listen one can safely say it again". My hope is that one can usefully say it again.

Surely it would not be impossible in this problem 
of enuresis to conduct a controlled trial in which the patients were started on a low dosage and, if necessary, and subject, of course, to toxicity and adverse reactions, stepped up to a higher dose? They could could still be compared with a group on a placebo and the trial would show whether by such adjustments in relation to the individual patient's needs, the group on imipramine, or some large proportion of it, could be stabilized on a dry bed.

\section{The Response Curve}

An alternative approach, here or elsewhere, would be to endeavour to establish a response-curve by the use of a different fixed-dose level for each of a number of groups of patients. If I were faced with another ti ial of a wonder drug to cure the common cold, I would certainly wish to consider this method.

What we did with the trial of an antihistaminic drug in 1950 was to choose the product that had been claimed as very effective (thonzylamine) and to choose a fixed dose of three $50 \mathrm{mg}$. tablets a day for 3 days. The effects of this régime were compared with those produced by a similar course of tablets containing $5 \mathrm{mg}$. quinine sulphate in a lactose base. The drug and control boxes of pills were distributed to the patients in a previously-constructed random order unknown to patient, nurse, or doctor. This method was adopted in place of the more usual one of labelling one product $X$ and the other $Y$ and giving them in random order because of the sideeffects to be expected with the drug. If decisive sideeffects were observed with even one patient, then the nature of $X$ (or $Y$ ) would be known or suspected (though subsequent experience showed often incorrectly).

With the random order of pill boxes the identity of one might be suspected in the patient showing side-effects but this would provide no evidence regarding the treatment of any other patient. Obviously this technique can be extended without difficulty so long, that is, as we can steer clear of toxicity and dangerous reactions. Subject to that proviso we could fill our pill boxes in random order with placebo, $50 \mathrm{mg}$., $75 \mathrm{mg}$., and $100 \mathrm{mg}$. The trial is still double-blind and can remain so until the results have been analysed.

Maybe it is not often that such trials would prove possible, but their possibility and value should not be overlooked and they should at least be carefully considered.

\section{Present and Past}

My final reflection is upon the situation in which it is impossible to repeat a published trial for ethical raasons. This situation is almost unique to medicine and is, of course, not at all uncommon in medicine

An interesting example (or what as a layman $\vec{P}$ take to be an example) is the treatment of patients with a myocardial infarction with potassium and: glucose given orally and insulin given subcutas? neously. Mittra (1965), working in Belfast, set up ao sequential trial and during 1964-65 admitted to it 17ळ6 patients, half of whom were given the specific treat ment and half of whom served as controls. The two groups were alike in relevant respects, the patientsi having been allocated randomly to them as soon after? their admission to hospital as possible.

Of the specifically-treated patients $11 \cdot 7$ per cent $\overrightarrow{\vec{\omega}}$ died during the 14 days of treatment, of the controls $28 \cdot 2$ per cent. The difference is clearly statistically significant and (more important) considerable How the treatment works is unknown.

It would be interesting to know to what extent its effects vary with agz, sex, and presenting severity of illness. But how ethically can one proceed either to check the broad result or to seek more detailed. answers hidden within?

According to my experience the customary method would be to give all new cases the specific treatmen 6 and then to seek in the case records of the hospital for past patients who could be adequately matched with the new patients. Difficulties arise because $(a)$ neces:sary observations or measurements are missing past records or $(b)$ more than one past case is rough matchable and knowing the upshot it may be difficulp to make an unbiased selection-or to convince the reader that it was an unbiased selection.

Possibly there might be some advantage in invert $\overrightarrow{\overline{0}}$ ing the process. In other words we should first draw up a file of all the past records over some choser interval of time-or of some sufflciently large cross section of them. By analysis of these data we could see (if we did not know already) what were the more important prognostic features in early mortality Then, as we admitted new cases for the specific treat ment, we would endeavour to match each one ing turn against these features in some specific past case In course of time we would in the normal way observe the response of each new case. Any new case that could not be matched would, of course, be treated but excluded from the trial. (Recent work has suggested that matching has no great advantage over randomization, but this certainly would non̂ apply here since there is no randomization and arf attempt must essentially be made to reach an equality of characteristics.)

Though I am no devotee of the present versus pase comparison, I have a feeling that this inversion of the usual approach might give a more acceptable answer 
than the usual approach. It obviously raises no ethical problem, for all new cases are treated.

\section{CONCLUSION}

In a comment upon the Medical Research Council's trial of anti-depressant drugs, William Sargant (1965) wrote "there is no psychiatric illness in which bedside knowledge and long clinical experience pays better dividends; and we are never going to learn how to treat depressions properly from double-blind sampling in an M.R.C. statistician's office".

I am sure he is right on both counts. Unfortunately, as one of the patients in the bed, I feel more than a trifle depressed while - partly at my expensehe gains his knowledge and his long clinical experience. I would have hoped that the process of learning might be a little less long if it were supported by the experimental method and attitude of mind.

Certainly we are never going to learn how to treat depressions, or any other illness, just from doubleblind sampling in a statistician's office. The statiscian's office, needless to say, merely provides an experimental design upon which to hang the skilled clinical observations that must characterize any form of inquiry into therapeutic efficacy. And the design is a collaborative creation. There is no question of replacing "valuable clinical observation by a series of mathematical symbols" (Marks, 1962). Those who think so have the myopia of Don Quixote; they mistake the scaffold for the house.
Fortunately, however, one visible feature of many of the clinical trials of to-day is the absence of a statistician. In this field of work the object of his life must be professional suicide. Once the clinician has grasped the simple techniques that have been brought to his aid, the statistician has no further part to play. Along with the old soldier he can fade away, contentedly if, sometimes, wistfully.

\section{REFERENCES}

Abrams, A. L. (1964). Amer. J. Psychiat., 121, 87.

Armitage, P. (1965). In "Medical Research Council Conference on Mathematics and Computer Science in Biology and Medicine", Proc. Conf. Oxford, 1964. H.M.S.O., London.

Bernard, C. (1865). "Introduction à l'étude de la médecine expérimentale." Baillière, Paris (Trans. H. C. Greene, 1927).

Binns, T. B., and Butterfield, W. J. H. (1964). Lancet, 1, 1150.

Brit. med.J. (1965), 2, 602.

Cromie, B. W. (1963). Lancet, $2,994$.

Hamilton, M. (1965). Brit. med. J., 2, 1048.

McMichael, J. (1964). Ibid., 2, 1007.

Marks, J. (1962). J. New Drugs, $2,71$.

Medical Research Council (1948). Brit. med.J., $2,769$. (1954). Ibid., 1, 1223.

(1964). Ibid., 2, 837.

Mittra, B. (1965). Lancet, 2, 607.

Platt, R. (1964). Ibid., 2, 949.

Sargant, W. (1965). Brit. med. J., 1, 1495. 